\title{
Investigation into mercury bound to biothiols: structural identification using ESI-ion-trap MS and introduction of a method for their HPLC separation with simultaneous detection by ICP-MS and ESI-MS
}

\author{
Eva M. Krupp • Bruce F. Milne • Adrien Mestrot • \\ Andrew A. Meharg • Jörg Feldmann
}

Received: 17 September 2007 /Revised: 10 December 2007 / Accepted: 11 December 2007 /Published online: 24 February 2008

(C) Springer-Verlag 2008

\begin{abstract}
Mercury in plants or animal tissue is supposed to occur in the form of complexes formed with biologically relevant thiols (biothiols), rather than as free cation. We describe a technique for the separation and molecular identification of mercury and methylmercury complexes derived from their reactions with cysteine (Cys) and glutathione (GS): $\mathrm{Hg}(\mathrm{Cys})_{2}, \mathrm{Hg}(\mathrm{GS})_{2}$, MeHgCys, MeHgGS. Complexes were characterised by electrospray mass spectrometry (MS) equipped with an ion trap and the fragmentation pattern of MeHgCys was explained by using MP2 and B3LYP calculations, showing the importance of mercuryamine interactions in the gas phase. Chromatographic baseline separation was performed within 10 min with formic acid as the mobile phase on a reversed-phase column. Detection was done by online simultaneous coupling of ES-MS and inductively coupled plasma MS. When the mercury complexes were spiked in real samples (plant extracts), no perturbation of the separation and detection conditions was
\end{abstract}

A part of this work was presented as a poster at the European Winter Conference on Plasma Spectrochemistry, 2007, held in Taormina, Italy.

E. M. Krupp $(\bowtie) \cdot$ A. Mestrot $\cdot$ J. Feldmann College of Physical Sciences, University of Aberdeen, Meston Walk,

Aberdeen AB24 3UE, UK

e-mail: e.krupp@abdn.ac.uk

B. F. Milne

Faculdade de Farmácia, Universidado de Porto,

Rua Aníbal Cunha 164,

Porto 4050-047, Portugal

A. A. Meharg

School of Biosciences, University of Aberdeen,

Tillydrone Avenue,

Aberdeen AB24 2TZ, UK observed, suggesting that this method is capable of detecting mercury biothiol complexes in plants.

Keywords Mercury - Methylmercury · Biothiols ·

High-performance liquid chromatography.

Electrospray mass spectrometry .

Inductively coupled plasma mass spectrometry .

Conformation modelling

\section{Introduction}

Mercury is one of the most important elements to consider when environmental pollution is concerned, and ever since the Minamata disaster in 1959, the organic compound methylmercury has been in focus owing to its enhanced toxicity and its biomagnification properties in the food chain [1].

Following the Minamata disaster, the differentiation of inorganic mercury in the form of $\mathrm{Hg}^{2+}$ from organic mercury, namely in the form of methylmercury, has become a major task. Mercury speciation in complex matrices is not easy to achieve [2], and more and more sophisticated analytical methods have been developed in the past few years in order to obtain reliable quantitative results. In particular, species-specific isotope dilution mass spectrometry (SSIDMS) employing stable mercury isotopes has been a major breakthrough [3,4]. Otherwise, experiments with stable isotope tracers introduced into the environment have given invaluable information on the distribution and transformation behavior of mercury in the environment [5-7]. Mercury has also been identified as a global pollutant, and the importance of new analytical methods 
towards a more complete understanding of species distribution, pathways and global impact has been highlighted recently [8].

As of today, the most common application of mercury speciation in biota is focused on the determination and distinction between methylmercury and inorganic mercury in the forms of $\mathrm{MeHg}^{+}$and $\mathrm{Hg}^{2+}$. To separate the mercury species from their matrix, usually extraction or soft digestion methods are applied, which conserve the $\mathrm{C}-\mathrm{Hg}$ bond, keeping the methylmercury moiety intact. However, it is more than unlikely that mercury and methylmercury occur as free cations, be it in biota or in the environment, and rather they are likely bound to sulfur-containing biomolecules, e.g. in fish [9], or present as chloride complexes, e.g. in seawater [10]. But, with the usual practice of mercury speciation, the counterion bound to the mercury species is lost and, even worse, completely disregarded. Thus, the information on the molecular entity of the mercury species is wasted-strictly speaking, this is not really speciation, but rather a fractionation method.

Now, in spite of the enormous progress made in mercury speciation, many questions relating to mercury and its behavior in biota remain unsolved mysteries: Why is methylmercury highly bioaccumulated, while $\mathrm{Hg}^{2+}$ is not? Why are different organs targeted by methylmercury as opposed to $\mathrm{Hg}^{2+}$, and how can the enormous latency period (up to several months!) for methylmercury intoxication be explained $[1,11]$ ?

Little is known today about the mechanisms that enable mercury uptake into cells, and its subsequent distribution and bioaccumulation in biota. But, mercury and methylmercury are well known to bind to biothiols abundant in biota and form stable complexes via $\mathrm{Hg}-\mathrm{S}$ bonds. Especially, in a model system, mercury complexes with cysteine (Cys) as a ligand have been found to be able to cross cell membranes, and the $\mathrm{Hg}(\mathrm{Cys})_{2}$ complex has been defined as a likely form in which $\mathrm{Hg}^{2+}$ is present. Zalups [12] and Bridges and Zalups [13] proposed that $\mathrm{Hg}(\mathrm{Cys})_{2}$ mimics the cystine molecule, and thus may use the active cell transport systems usually used for cystine transport into the cell. Although the theory of molecular mimicry has recently been questioned using structural comparison obtained from $\mathrm{X}$-ray absorption studies of the complexes concerned [14], it is still commonly agreed that mercury and methylmercury are most likely bound to and transported as complexes formed with biothiols abundant in biota. Other studies employing direct speciation methods in biota, like extended $\mathrm{X}$-ray absorption fine structure and X-ray absorption nearedge structure, underpin the assumption that methylmercury and mercury are bound to sulfur in a complex matrix [9].

Although mercury biothiol complexes have not been identified in vivo so far, mercury biothiols certainly play a key role in cell uptake, distribution and subsequently toxicity of mercury in biota [1, 11-13]. But, even state-ofthe-art analytical methods for mercury speciation fail to provide us with all the necessary information, i.e. the complete molecular structure of the mercury compounds present in vivo.

Therefore, our interest lies in the development of an analytical method that allows the direct detection of mercury and methylmercury biothiol complexes in biota.

In this paper, we describe an analytical method allowing the species identification of mercury and methylmercury biothiols as intact molecules. As example species, Cys and glutathione (GS) complexes with mercury and methylmercury were synthesised and analysed. Cys is a small sulfur-containing amino acid, while GS is a small peptide comprising only three amino acids: $\gamma$-glutamyl $(\gamma$-Glu), Cys and glycine (Gly). Like Cys, this compound is usually abundant in living cells in millimolar concentrations, and it is a key compound for the cell's redox state control: GS is the smallest building block for the synthesis of phytochelatins, which are produced in plants as a response to metal stress, and are believed to play a paramount role in metal detoxification in plants [15]. Plants are well known to accumulate mercury when grown on polluted soil $[16,17]$, and a future object of study for mercury exposure will be rice (Oryza sativa); therefore, we tested the method and the species stability in the matrix of a real plant extract derived from rice plants.

\section{Experimental}

\section{Instrumentation}

The instrumentation used for this work consisted of an Agilent Technologies (USA) suite comprising an 1100 series high-performance liquid chromatography (HPLC) system, an electrospray mass spectrometer (ES-MS) (XCT ion-trap mass spectrometer) and an inductively coupled plasma mass spectrometer (ICP-MS) (7500 c series). The HPLC system was equipped with an automatic degasser, a gradient pump, a thermostated autosampler tray and a thermostated column device.

For the chromatographic separation of the mercury biothiols, an HPLC method was adapted from that of Raab et al. [18]. Species separation was carried out using an Agilent Zorbax Eclipse XDB C-18 $(4.6 \mathrm{~mm} \times 150 \mathrm{~mm}$, $5-\mu \mathrm{m})$ reversed-phase (RP) HPLC column using a gradient elution with eluent $\mathrm{A}$ being $0.1 \%$ formic acid in water and eluent B being $0.25 \%$ formic acid in methanol. The gradient programme went from $100 \%$ eluent $\mathrm{A}$ to $50 \%$ eluent $B$ in $20 \mathrm{~min}$ with a flow rate of $1 \mathrm{~mL} / \mathrm{min}$, and a volume of $50 \mu \mathrm{L}$ was injected via the autosampler. The autosampler tray was cooled to $4{ }^{\circ} \mathrm{C}$ for all experiments. 
Coupling of the HPLC instrument to the ES-MS and ICP-MS system was performed either individually using PEEK capillary tubing $(1.6-\mathrm{mm}$ outer diameter, $0.3-\mathrm{mm}$ inner diameter), or simultaneously via a micro flow splitter (Upchurch, UK). In split mode for simultaneous coupling, $80 \%$ of the HPLC eluent was directed into the ES-MS system, while $20 \%$ went into the ICP-MS system.

$\mathrm{Hg}(\mathrm{Cys})_{2}, \mathrm{HgMeCys}, \mathrm{Hg}(\mathrm{GS})_{2}$ and $\mathrm{HgMeGS}$ solutions were prepared as described above in concentrations of $10 \mathrm{mg} / \mathrm{L}$ (as $\mathrm{Hg}$ ), each in $0.1 \%$ formic acid. From these solutions, a mixture containing all four compounds was prepared at equal concentrations, resulting in a solution with a concentration of $2.5 \mathrm{mg} / \mathrm{L}$ (as $\mathrm{Hg}$ ) of each compound.

A continuous internal standard (Rh, $20 \mu \mathrm{g} / \mathrm{L}$ ) was mixed with the HPLC effluent prior to the ICP-MS nebuliser via a Teflon T-piece. This internal standard enables the monitoring of overall instrument sensitivity and plasma conditions, and may potentially be used to correct the mercury signal for changes in intensity due to matrix effects stemming from the introduction of methanol during gradient elution [19].

The ES-MS system was also used in direct injection mode for the species' fragmentation experiments. Here, the sample was introduced into the ES source via a syringe pump using a $1-\mathrm{mL}$ glass syringe. The ES-MS and ICP-MS instrumentation parameters can be found in Table 1 .

\section{Reagents}

All reagents used were of analytical grade and were purchased from Sigma-Aldrich, UK, unless mentioned otherwise. The water used for all the preparations was of suprapure quality (18 M $\Omega$, ELGA water system, UK). HPLC eluents were prepared from formic acid at $0.1 \%$ in $\mathrm{H}_{2} \mathrm{O}$ and $0.25 \%$ in methanol.

An inorganic mercury $\left(\mathrm{Hg}^{2+}\right)$ standard stock solution at approximately $1,000 \mathrm{mg} / \mathrm{kg}$ (as $\mathrm{Hg}$ ) was prepared by dissolving solid $\mathrm{HgCl}_{2}$ in water. A methylmercury $\left(\mathrm{MeHg}^{+}\right)$ standard stock solution at approximately $1,000 \mathrm{mg} / \mathrm{kg}$ (as $\mathrm{Hg}$ ) was prepared from solid $\mathrm{MeHgCl}$ in methanol. For the preparation of mercury and methylmercury biothiols, these stock solutions were further diluted in $0.1 \%$ formic acid. The water for the preparation of standards was degassed using ultrasonication $\left(10 \mathrm{~min}\right.$ ) followed by purging with $\mathrm{N}_{2}$ $(10 \mathrm{~min}$ at $200 \mathrm{~mL} / \mathrm{min})$. Stock solutions were kept in a freezer at $-20{ }^{\circ} \mathrm{C}$; further dilutions were kept for a maximum of 1 week at $4{ }^{\circ} \mathrm{C}$ in the dark.

Reduced 1-cysteine and reduced GS were dissolved in water at a concentration of $1 \mathrm{mg} / \mathrm{mL}$ and were prepared fresh daily.

Synthesis of $\mathrm{HgMeCys}, \mathrm{HgMeGS}, \mathrm{Hg}(\mathrm{Cys})_{2}$ and $\mathrm{Hg}(\mathrm{GS})_{2}$

From solutions prepared as described above, mercury and methylmercury biothiols were synthesised by stoichiomet-
Table 1 ICP-MS and ES-MS parameters

\begin{tabular}{|c|c|}
\hline Instrument & Settings \\
\hline \multicolumn{2}{|l|}{$I C P-M S$} \\
\hline Instrument & Agilent Technologies $7500 \mathrm{c}$ \\
\hline Torch & Standard \\
\hline \multicolumn{2}{|l|}{ Ar gas flows } \\
\hline Cooling gas & $16 \mathrm{~L} / \mathrm{min}$ \\
\hline Auxiliary gas & $1 \mathrm{~L} / \mathrm{min}$ \\
\hline Nebuliser gas & $0.95 \mathrm{~L} / \mathrm{min}$ \\
\hline Optional gas: $\left(\mathrm{O}_{2}\right)$ & $5 \%$ \\
\hline Spray chamber & Scott, cooled $\left(2{ }^{\circ} \mathrm{C}\right)$ \\
\hline Nebuliser & PFA, microconcentric \\
\hline Internal standard & $\begin{array}{l}\text { Continuous aspiration, } 20 \mu \mathrm{g} / \mathrm{L} \mathrm{Rh} \text { in } 1 \% \\
\mathrm{HNO}_{3}\end{array}$ \\
\hline Cones & Platinum \\
\hline $\begin{array}{l}\text { Isotopes } \\
\text { monitored }\end{array}$ & ${ }^{200} \mathrm{Hg},{ }^{202} \mathrm{Hg},{ }^{103} \mathrm{Rh},{ }^{34} \mathrm{~S},{ }^{32} \mathrm{~S}{ }^{16} \mathrm{O}$ \\
\hline \multicolumn{2}{|l|}{ ES-MS } \\
\hline Instrument & $\begin{array}{l}\text { Agilent Technologies XCT ion-trap mass } \\
\text { spectrometer }\end{array}$ \\
\hline Ion source & Electrospray ionisation \\
\hline Capillary voltage & $4,500 \mathrm{~V}$ \\
\hline Nebuliser pressure & $\begin{array}{l}\text { HPLC } 50 \text { psi }(0.345 \mathrm{MPa}) \text {; direct injection } \\
20 \mathrm{psi}(0.138 \mathrm{MPa})\end{array}$ \\
\hline Drying gas & HPLC $12 \mathrm{~L} / \mathrm{min}$; direct injection $5 \mathrm{~L} / \mathrm{min}$ \\
\hline Gas temperature & $350{ }^{\circ} \mathrm{C}$ \\
\hline Scan window & $\mathrm{m} / \mathrm{z} 100-900$ \\
\hline $\begin{array}{l}\mathrm{MS}^{2} \text { fragmentation } \\
\text { window }\end{array}$ & $\mathrm{m} / \mathrm{z} 4$ \\
\hline
\end{tabular}

PFA perfluoroalkoxy, HPLC high-performance liquid chromatography, $M S^{2}$ Ion trap

rically adding the respective amounts of dissolved biothiol (GS or Cys) to a defined volume of mercury or methylmercury solution. All steps were carried out in a glove bag under a $\mathrm{N}_{2}$ atmosphere in order to avoid oxidation of the thiols. Usually, mercury-thiol compounds were prepared fresh daily.

Modelling the MeHgCys conformation: ab initio and density functional theory calculations

The conformation of $\mathrm{MeHgCys}$ might involve bonding via either an oxygen atom in the carboxylic group or a nitrogen atom from the amino group, and either an uncharged or zwitterionic form could be possible. In an attempt to predict which, if any, of these conformations/configurations might be favoured in the gas phase, a series of ab initio and density functional theory (DFT) calculations were performed on a variety of possible structures. Geometry optimisations were performed using the electronic structure software GAMESS-US [20] at both the DFT B3LYP and the ab initio MP2 levels of theory. The 7 September 2006 release of GAMESS-US was used for the DFT calculations and the 
24 March 2007 release was used for the MP2 calculations. In both sets of calculations the $6-31 \mathrm{G}(\mathrm{d}, \mathrm{p})$ basis set [21] was employed for all atoms with the exception of mercury, which was described by the SBKJC effective core potential basis [22]. A subsequent vibrational analysis at the optimised geometries showed them to be true minima and also provided zero-point energies (ZPEs) for use in correcting the energies obtained from the minimisations. The ZPEs were scaled by 0.961 (B3LYP) and 0.9646 (MP2) as suggested by the collected data available online from the CCCBDB database at http://srdata.nist.gov/cccbdb/. The relative populations of the conformers with the lowest ZPEcorrected energies were estimated by calculating the ratios of the Boltzmann factors [23] at $350{ }^{\circ} \mathrm{C}$, which is the gas temperature inside the ES ion source.

\section{Plant preparation}

Rice (Oryza sativa) was grown from seeds in vermiculite medium and fed with regular Hoagland solution [24] three times a week. After 2 months of growth, the rice plants were harvested. The vermiculite was washed off the roots, and the plants were sectioned into roots and shoots, cut into pieces of approximately $5 \mathrm{~mm}$ length. Extracts were prepared according to the method of Raab et al. [25]. Briefly, $1 \mathrm{~g}$ of plant material was ground in a mortar under addition of liquid $\mathrm{N}_{2}$, the sample was transferred into a $15-\mathrm{mL}$ Greiner tube, $3 \mathrm{~mL}$ of $1 \%$ formic acid was added and the mixture was left standing in ice at $0{ }^{\circ} \mathrm{C}$ for $1 \mathrm{~h}$.

\section{Results and discussion}

The objective of this work was to develop an analytical method for the separation and identification of mercury and methylmercury bound to Cys and GS. Structural MS carried out here using an ES mass spectrometer equipped with an ion trap was used as a tool for the identification and structural characterisation on a molecular level. The information gained via the fragmentation pattern obtained from the ion-trap measurements proves invaluable for the identification of unknown molecules, along with some information on the molecules' conformation, while the simultaneous element-selective detection of mercury via ICP-MS is the key to identifying mercury-containing biomolecules in a complex matrix amidst a variety of other organic molecules.

More detailed information on the conformation of the $\mathrm{HgMeCys}$ molecule was obtained by a modelling approach, which underpins the findings of ion-trap ES-MS.

In this paper, we focus on the structural identification of the selected mercury and methylmercury biomolecules via ion-trap ES-MS after their separation using RP HPLC.
Here, all mercury compounds were measured under the same detection conditions, and all ES-MS parameters were kept constant for all four species during direct injection as well as in HPLC injection mode. Simultaneous detection with ICP-MS was applied with HPLC separation for mercury-selective determination.

Ion-trap ES-MS measurements of $\mathrm{HgMeCys}, \mathrm{HgMeGS}$, $\mathrm{Hg}(\mathrm{Cys})_{2}$ and $\mathrm{Hg}(\mathrm{GS})_{2}$ using direct sample injection

In a first approach of identification, mercury and methylmercury complexes with Cys and GS, synthesised as described earlier in $0.1 \%$ formic acid at a concentration of $50 \mathrm{mg} / \mathrm{kg}$ (as Hg) each, were injected as single standards into the ES source of the ion-trap MS instrument. The ESMS parameters can be found in Table 1 .

The species identification was performed by using information obtained from the ES-MS and ion-trap MS data:

- $\quad$ The $\mathrm{MH}^{+}$molecule cluster

- The characteristic isotope pattern dominated by the mercury isotope distribution

- In-source fragmentation of the mercury biomolecule Cys and GS moieties

- Ion trap MS $\left(\mathrm{MS}^{2}\right)$ of the $\mathrm{MH}^{+}$molecular ion peak

In Fig. 1, the ES-MS spectra measured for the molecular ions $\left(\mathrm{MH}^{+}\right)$of the four compounds are shown. The vertical black lines represent the theoretical isotope ratio pattern of the molecules according to their molecular structure.

The mercury isotope pattern is very prominent, it dominates the overall isotope pattern of the molecules, and can therefore be used as a characteristic fingerprint: In small mercury biomolecules, the mercury isotope pattern is greatly preserved, even when the organic molecular structure, like in $\mathrm{HgGS}_{2}$, accounts for $75 \%$ of the molecular mass. The mass spectra show that under the ionisation conditions applied, the mercury compounds are protonated and detected by the ES-MS instrument as a molecule cluster. The experimentally obtained isotope cluster for $\mathrm{MH}^{+}$match well with the theoretical isotopic molecule patterns calculated for each compound. The major isotope in the clusters is here referred to as the $100 \%$ abundance isotope, reflecting the usual practice in isotope abundance visualisation by defining the major mass as $100 \%$ and the less abundant isotopes as fractions of this.

In-source fragmentation of $\mathrm{HgMeCys}$, $\mathrm{HgMeGS}, \mathrm{Hg}(\mathrm{Cys})_{2}$ and $\mathrm{Hg}(\mathrm{GS})_{2}$

Molecule fragmentation is usually observed during the ionisation step in the ES ion source. The fragmentation pattern obtained in this process gives information about the 


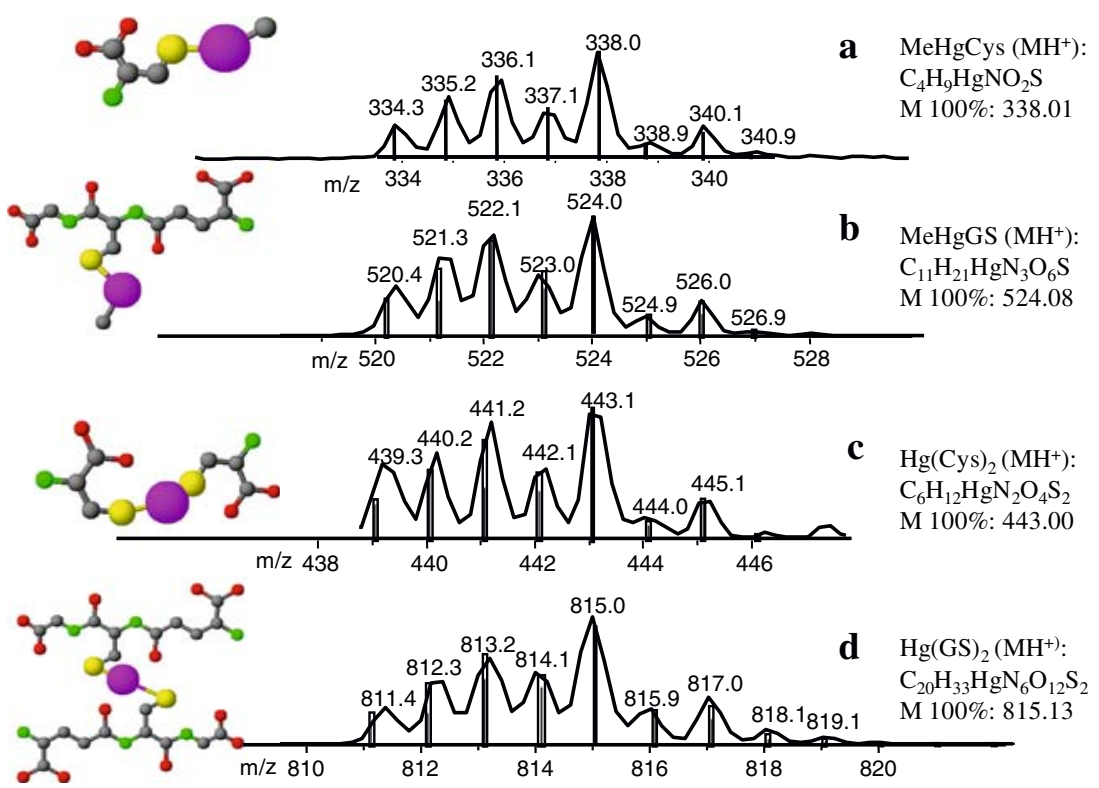

Fig. 1 Electrospray (ES) mass spectrometry (MS) spectra of the $\mathrm{MH}^{+}$ peak cluster for four mercury biothiol compounds (direct injection of single standards). The theoretical isotope pattern is shown as vertical black lines. Molecular structures as ball-and-stick models are shown on the left (Hg violet, S yellow, O red, $\mathrm{N}$ green, C grey, H not shown).
Theoretical isotope abundance is matched to the highest-abundance peak, set at $100 \%$. The exact mass (theoretical) is given for the $100 \%$ peak. a MeHgCys. b $\mathrm{MeHgGS}$. c $\mathrm{Hg}(\mathrm{Cys})_{2}$. d $\mathrm{Hg}(\mathrm{GS})_{2}$. Cys cysteine, $G S$ glutathione
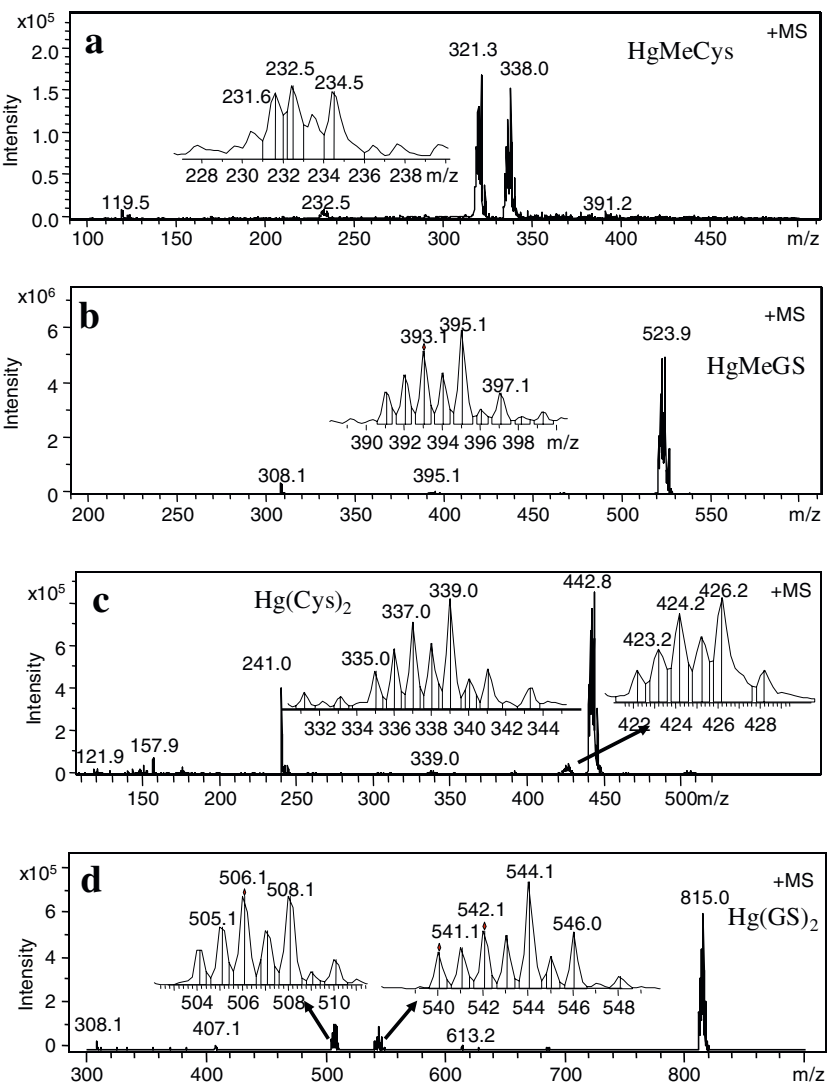

Fig. 2 ES-MS spectra $\left(\mathrm{MS}^{+}\right)$showing the in-source fragmentation for four mercury biothiol compounds (direct injection of single standards). a MeHgCys. b MeHgGS. c $\mathrm{Hg}(\mathrm{Cys})_{2}$. d Hg(GS) source fragments observed. In-source fragmentation can be 
influenced by ionisation parameters, such as capillary voltage. Here, the parameters used were as detailed in Table 1 for the direct-injection mode.

From Fig. 1 it is evident that from the four mercury compounds investigated only $\mathrm{MeHgCys}$ (Fig. 1a) shows extensive in-source fragmentation, resulting in two clusters of approximately the same peak height: the $\mathrm{MH}^{+}$cluster with $\mathrm{m} / \mathrm{z} 338$ as the $100 \%$ abundance isotope and a second cluster with $\mathrm{m} / \mathrm{z} 321$ as the $100 \%$ abundance isotope, showing a mass loss of 17 from the $\mathrm{MH}^{+}$molecular ion cluster. This mass loss can be attributed to the loss of either $\mathrm{OH}$ or $\mathrm{NH}_{3}$. Apart from the two most prominent in-source fragments, only one fragment exhibiting a mercury-like isotope pattern can be found at $m / z$ 234. This may be attributed to a $\mathrm{MeHg}-\mathrm{NH}_{3}^{+}$or a $\mathrm{MeHgOH}$ moiety, and accounts for just $3 \%$ of the combined peak areas of the two main peaks. Similar fragmentation has been described by D'Agostini et al. [26], who suggested the loss of $\mathrm{NH}_{3}$ from the $\mathrm{MH}^{+}$ion, and hypothesised that two isomeric species of $\mathrm{MeHgCys}$ are present in solution, either exhibiting a $\mathrm{Hg}-\mathrm{N}$ or a $\mathrm{Hg}-\mathrm{O}$ interaction. Here, we show that the $\mathrm{Hg}-\mathrm{N}$ interaction is the most likely form present in the ion source, and that the in-source fragment at $\mathrm{m} / \mathrm{z} 321$ is indeed most likely formed through loss of $\mathrm{NH}_{3}$. This was achieved through the ion-trap $\mathrm{MS}^{2}$ fragmentation pattern and a modelling approach, in which the most stable conformation for $\mathrm{MeHgCys}$ was calculated in the gas phase. These experiments are highlighted further below.

A fragment with mass 119.5 may be attributed to free Cys or cystine (doubly charged), but occurs at less than $1 \%$ abundance compared with the two main clusters. The absence of free Cys also suggests that the complex is formed quantitatively in the solution.

Figure $2 \mathrm{~b}$ shows the in-source fragmentation of MeHgGS during direct injection, clearly showing the $\mathrm{MH}^{+}$molecular peak cluster as the dominant component. Two more fragment peaks can be identified. One fragment at $\mathrm{m} / \mathrm{z} 395$, exhibiting a cluster with the typical mercury isotope pattern, can be attributed to a loss of the $\gamma$-Glu moiety from GS. A second peak appears at $\mathrm{m} / \mathrm{z} 308$, which can be clearly attributed to protonated GS. The spectrum shows the MeHgGS molecule peak prevailing with more than 95\% abundance, while the two other fragments observed correspond to approximately $1 \% \mathrm{MH}^{+}$abundance only.

For $\mathrm{Hg}(\mathrm{Cys})_{2}$ (Fig. 2c), $\mathrm{MH}^{+}$is the most prominent peak in the spectrum. An in-source fragment obtained from a mass loss of 17 is also observed, but accounts for less than $6 \%$ of the $\mathrm{MH}^{+}$peak only. Another fragment with the typical mercury isotope pattern and $\mathrm{m} / \mathrm{z} 339$ the $100 \%$ abundance peak may be attributed to a $\mathrm{Cys}-\mathrm{Hg}-\mathrm{NH}_{3}^{+}$ moiety, similar to the fragment observed for MeHgCys: a Cys group can obviously be cleaved from the molecule, leaving a $\mathrm{Hg}-\mathrm{N}$ bond behind. Two more peaks can be distinguished at $\mathrm{m} / \mathrm{z} 241$ and $\mathrm{m} / \mathrm{z} 122$, corresponding to protonated cystine (Cys-Cys) and Cys. Cystine at $\mathrm{m} / \mathrm{z} 241$ seems quite abundant, but accounts for only $10 \%$ of the $\mathrm{MH}^{+}$cluster of $\mathrm{Hg}(\mathrm{Cys})_{2}$. Only traces of free Cys at $\mathrm{m} / \mathrm{z}$ 122 (less than $1 \%$ of the mercury molecular cluster) were found.

The spectrum of $\mathrm{Hg}(\mathrm{GS})_{2}$ (Fig. 2d) shows two mercurycontaining fragments at $\mathrm{m} / \mathrm{z} 544$ and $\mathrm{m} / \mathrm{z} 508$ besides the most prominent peak for $\mathrm{MH}^{+}$at $m / z$ 815. While $m / z 508$ can clearly be attributed to a protonated HgGS fragment after loss of one GS group, the cluster at $\mathrm{m} / \mathrm{z} 544$ cannot be clearly identified, but might be a Hg-GS cluster with two water molecules associated. A peak at $m / z 407$ corresponds to the doubly charged molecule peak $\mathrm{MH}^{2+}$. Two more peaks can be distinguished: $\mathrm{m} / \mathrm{z} 613$, corresponding to protonated oxidised GS, and $\mathrm{m} / \mathrm{z} 308$, corresponding to free reduced GS.

The two mercury-containing fragments correspond to $10 \%(\mathrm{~m} / \mathrm{z} 544)$ and $15 \%(\mathrm{~m} / \mathrm{z} 508)$, respectively, of the overall abundance, while the protonated oxidised and reduced GS only account for approximately $1 \%$ each, and $\mathrm{MH}^{2+}$ accounts for less than $2 \% . \mathrm{MH}^{+}$is found to occur at more than $70 \%$.

The ionisation efficiencies differ substantially between the four different compounds: While MeHgCys exhibits the lowest intensities, with $2 \times 10^{5}$ counts, the MeHgGS signal is tenfold higher. $\mathrm{Hg}(\mathrm{Cys})_{2}$ and $\mathrm{Hg}(\mathrm{GS})_{2}$, each with around $5 \times 10^{5}$ counts, show intensities between these two. Taking into account that $\mathrm{MeHgCys}$ forms an abundant in-source fragment with the same intensity as the $\mathrm{MH}^{+}$ion, these three molecules appear to have similar ionisation behaviour, leading to comparable ratios of protonation in the ES source under the conditions applied.

Conformation of HgMeCys: ion-trap $\mathrm{MS}^{2}$ fragmentation and conformation modelling

Collision-induced fragmentation was performed using the ion-trap device of the ES-MS instrument. The in-source fragmentation of MeHgCys showed an important fragment with a mass loss of $17 \mathrm{amu}$ with abundance as high as the $\mathrm{MH}^{+}$molecular ion. This mass loss can be explained by either loss of $\mathrm{OH}$ or $\mathrm{NH}_{3}$ from $\mathrm{MH}^{+}$, and both possibilities have been postulated before [26]. Here, we use the ion-trap $\mathrm{MS}^{2}$ information on the two prevailing peaks obtained combined with a modelling approach to find the most probable conformation of MeHgCys, which may explain the fragmentation behaviour observed.

As shown in Fig. 3, the $\mathrm{MS}^{2}$ spectrum of the MeHgCys molecular ion $\left(\mathrm{m} / \mathrm{z} 336,{ }^{200} \mathrm{Hg}\right)$ shows a predominant fragment at $m / z 318$ due to loss of $\mathrm{H}_{2} \mathrm{O}$. A second fragment at $m / z 231$ can be attributed to either $\mathrm{MeHg}-\mathrm{NH}_{2}^{+}$or $\mathrm{MeHg}-\mathrm{O}^{+}$, formed through rearrangement of the molecule 

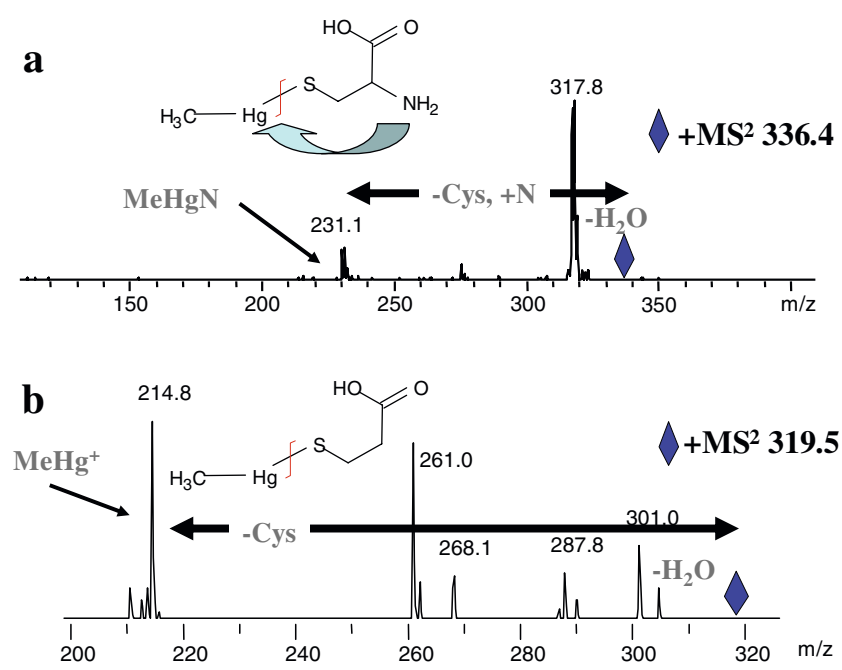

Fig. 3 Ion trap MS $\left(\mathrm{MS}^{2}\right)$ spectra as obtained from collision-induced fragmentation in the ion-trap device from the two main in-source fragments obtained from the direct injection of a single standard of MeHgCys. a $\mathrm{MS}^{2}$ of $\mathrm{MH}^{+}$at $m / z 336\left(\mathrm{Me}^{200} \mathrm{HgCys}\right)$. b $\mathrm{MS}^{2}$ of $\mathrm{MH}^{+}$ at $m / z 319\left(\mathrm{Me}^{200} \mathrm{HgCys}-\mathrm{OH}\right.$ or $\left.\mathrm{Me}^{200} \mathrm{HgCys}-\mathrm{NH}_{3}\right)$

under loss of the residual Cys moiety, and corresponds to the fragmentation pattern obtained in source. This finding is an indication that the $\mathrm{Hg}-\mathrm{S}$ bond is not the only interaction between $\mathrm{Cys}$ and $\mathrm{HgMe}$, but that either $\mathrm{Hg}-\mathrm{O}$ or $\mathrm{Hg}-\mathrm{N}$ bonding is involved, i.e. either the carboxylic or the ammonia group forms a bond to the central metal.

A different picture is seen when $\mathrm{MS}^{2}$ is performed on the in-source fragment ion with $\mathrm{m} / \mathrm{z} 319$ (formed through loss of $\mathrm{OH}$ or $\mathrm{NH}_{3}$ from ${ }^{200} \mathrm{HgMH}^{+}$at $m / z$ 336). Here, we can distinguish several fragments: $m / z 301$ (loss of $\mathrm{H}_{2} \mathrm{O}$ ), $\mathrm{m} / \mathrm{z}$ 288 and $\mathrm{m} / \mathrm{z} 261$, formed through the successive loss of parts of the Cys moiety, and $\mathrm{m} / \mathrm{z} 215$, corresponding to $\mathrm{MeHg}^{+}$. In contrast to the $\mathrm{MS}^{2}$ of $\mathrm{MH}^{+}(m / z 336)$, the fragment at $m / z 231$ is not formed. This is an indication that the group forming this fragment has been lost during insource fragmentation.

Modelling the $\mathrm{MeHgCys}$ conformation using ab initio and DFT calculations

The conformation of MeHgCys can involve either bonding via an oxygen atom in the carboxylic group or a nitrogen atom from the ammonia group, and can carry the proton at either group. A modelling approach was used to determine the total energies for the different possible conformations of $\mathrm{HgMeCys}$, including correction for the ZPE.

The final conformations obtained from the geometry optimisations at the MP2 level are shown in Fig. 4 (conformers 1-6). Those obtained from the B3LYP calculations differed only by small deviations in bond lengths and angles and are therefore not shown. Two of the geometry optimisations were started in zwitterionic config- urations with either a carboxylic oxygen (conformer 1) or the amino nitrogen (conformer 2) positioned close to the mercury atom. The zwitterionic form of MeHgCys was found to be unstable and optimisations led to the neutral form regardless of the initial protonation state. Of the remaining calculations, conformer 3 and 4 were started with the amino nitrogen close to the mercury, whereas conformers 5 and 6 were started with a carboxylic oxygen in this position. In all of these optimisations the initial $\mathrm{Hg}-\mathrm{X}$ ( $\mathrm{X}$ is $\mathrm{O}$ or $\mathrm{N}$ ) interaction was retained throughout, suggesting that this is generally favoured in the conformational behaviour of MeHgCys.

The pattern of relative conformational energies (Table 2) is basically the same at both levels of theory, with the most energetically favoured conformations displaying the $\mathrm{Hg}-\mathrm{N}$ interaction. Those conformations displaying $\mathrm{Hg}-\mathrm{O}$ interaction make up the second-most thermodynamically stable grouping, whereas the extended conformer where the mercury atom is free from nonbonded interaction is considerably higher in energy than all the others. The energy differences are more pronounced at the MP2 level than at the B3LYP level and this is probably due to the fact that the perturbation theory treatment is capable of describing dispersion effects, whereas DFT is not. Dispersion effects are responsible for mediating nonbonded interactions such as hydrogen bonds and van der Waals "bonds" and therefore it would be expected that these
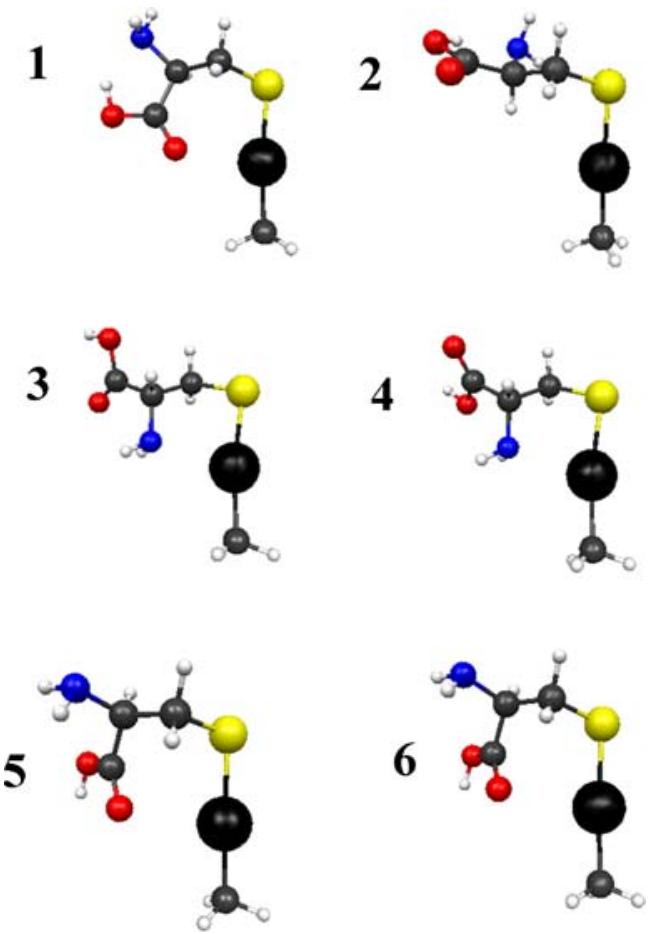

Fig. 4 Modelling the MeHgCys conformation: final conformations of $\mathrm{MeHgCys}$ obtained from geometry optimisation at the MP2 level. Model numbers $(1-6)$ as used in Table 2 
Table 2 Conformational energies obtained for the two different models used

\begin{tabular}{lll}
\hline Conformer & $\begin{array}{l}\mathrm{B} 3 \mathrm{LYP} / 6-31 \mathrm{G}(\mathrm{d}, \mathrm{p}) \Delta E \\
(\mathrm{~kJ} / \mathrm{mol})^{\mathrm{a}}\end{array}$ & $\begin{array}{l}\mathrm{MP} 2 / 6-31 \mathrm{G}(\mathrm{d}, \mathrm{p}) \Delta E(\mathrm{~kJ} / \\
\mathrm{mol})^{\mathrm{b}}\end{array}$ \\
\hline 1 & 7.4 & 18.0 \\
2 & 12.7 & 30.3 \\
3 & 0.0 & 0.0 \\
4 & 7.6 & 6.9 \\
5 & 25.8 & 21.0 \\
6 & 13.7 & 21.4 \\
\hline
\end{tabular}

Scale factors obtained from the CCCBDB database at http://srdata. nist.gov/cccbdb/

${ }^{a}$ Zero-point energies scaled by 0.9610

${ }^{\mathrm{b}}$ Zero-point energies scaled by 0.9646

would be important in this particular case. For this reason, the MP2 results are expected to be more reliable than those obtained with DFT since the former provide a more complete physical picture of the MeHgCys system.

The results of the Boltzmann factor calculations based on the corrected MP2 energies indicate that at the experimental temperature approximately $98 \%$ of the $\mathrm{MeHgCys}$ would be present as the form displaying the $\mathrm{Hg}-\mathrm{N}$ interaction, with the remaining $2 \%$ consisting almost exclusively of the $\mathrm{Hg}-\mathrm{O}$ forms. Using the B3LYP energies, these calculations suggest that the slightly lower figure of $87.5 \%$ for the $\mathrm{Hg}-\mathrm{N}$ forms, with one of the $\mathrm{Hg}-\mathrm{O}$ conformers making up most of the remaining population. As the MP2 energies are thought to be more accurate on the basis of physical considerations, it is reasonable to assume that the figure of $98 \%$ for the $\mathrm{Hg}-\mathrm{N}$ population is similarly more accurate; however, even at the B3LYP level the figures clearly point to this being the form of the molecule expected to be dominant in the gas phase at $350{ }^{\circ} \mathrm{C}$. The use of larger and/or more flexible basis sets might lead to alterations in these results owing to improved description of the $\mathrm{Hg}-\mathrm{X}$ interactions but it is felt that this would be unlikely to significantly alter the distribution of energies in this case.

Assuming that the $\mathrm{Hg}-\mathrm{N}$ form is dominant in the ion source, it is reasonable to assume that the in-source fragment obtained at $\mathrm{m} / \mathrm{z} 234\left({ }^{202} \mathrm{Hg}\right)$ corresponds to a (protonated) $\mathrm{MeHg}-\mathrm{NH}_{3}^{+}$ion. This is confirmed by the occurrence of the same fragment in $\mathrm{MS}^{2}$ at $\mathrm{m} / \mathrm{z} 231$ $\left(\mathrm{Me}^{200} \mathrm{Hg}-\mathrm{NH}_{2}^{+}\right)$. The in-source fragment at $\mathrm{m} / z 319$ $\left({ }^{200} \mathrm{Hg}\right)$ does not exhibit the $\mathrm{m} / \mathrm{z} 231$ fragment during $\mathrm{MS}^{2}$, but loses the Cys completely, with $\mathrm{MeHg}^{+}$remaining as the smallest mercury-incorporating fragment. This is suggestive of the possibility that the in-source fragment with $\mathrm{m} / \mathrm{z} 319$ has lost $\mathrm{NH}_{3}$ rather than $\mathrm{OH}-\mathrm{a} \mathrm{MeHg}-\mathrm{N}$ fragment cannot be formed from this mother ion. However, it should be noted that besides the $\mathrm{Hg}-\mathrm{N}$ interaction, a small contribution of $\mathrm{Hg}-\mathrm{O}$ is possible.
Ion-trap $\mathrm{MS}^{2}$ of the $\mathrm{MH}^{+}$cluster of $\mathrm{Hg}(\mathrm{Cys})_{2}$, $\mathrm{HgMeGS}$ and $\mathrm{Hg}(\mathrm{GS})_{2}$

Figure 5 depicts the ion-trap fragmentation patterns obtained for the three remaining mercury-containing biomolecules. The $m / z$ values of the $\mathrm{MS}^{2}$ spectra shown here in Fig. 5 are each defined for the ${ }^{200} \mathrm{Hg}$ isotope. However, the chosen trap window ion width of 4 amu ensures that a major part of the ion cluster is trapped and undergoes collision-induced fragmentation. Thus, easier identification of mercury-containing fragments is possible, as the mercury pattern is greatly conserved. However, the fragment incorporating ${ }^{200} \mathrm{Hg}$ will be trapped with the highest abundance.

\section{$\mathrm{Hg}(\mathrm{Cys})_{2}$}

The ion-trap collision-induced fragmentation of $\mathrm{Hg}(\mathrm{Cys})_{2}$ exhibits a most abundant fragment at $\mathrm{m} / \mathrm{z} 434$, corresponding to the loss of $\mathrm{H}_{2} \mathrm{O}$, and a second important fragment at $m / z 337$, which corresponds to the loss of one Cys molecule leaving a nitrogen atom bound to mercury $\left(\mathrm{CysHg}-\mathrm{N}^{+}\right)$. This behaviour is similar to what was found for the fragmentation of MeHgCys, and seems to be typical for mercury bound to a Cys moiety. No other fragments containing mercury can be observed, and no unbound Cys molecules were detected.
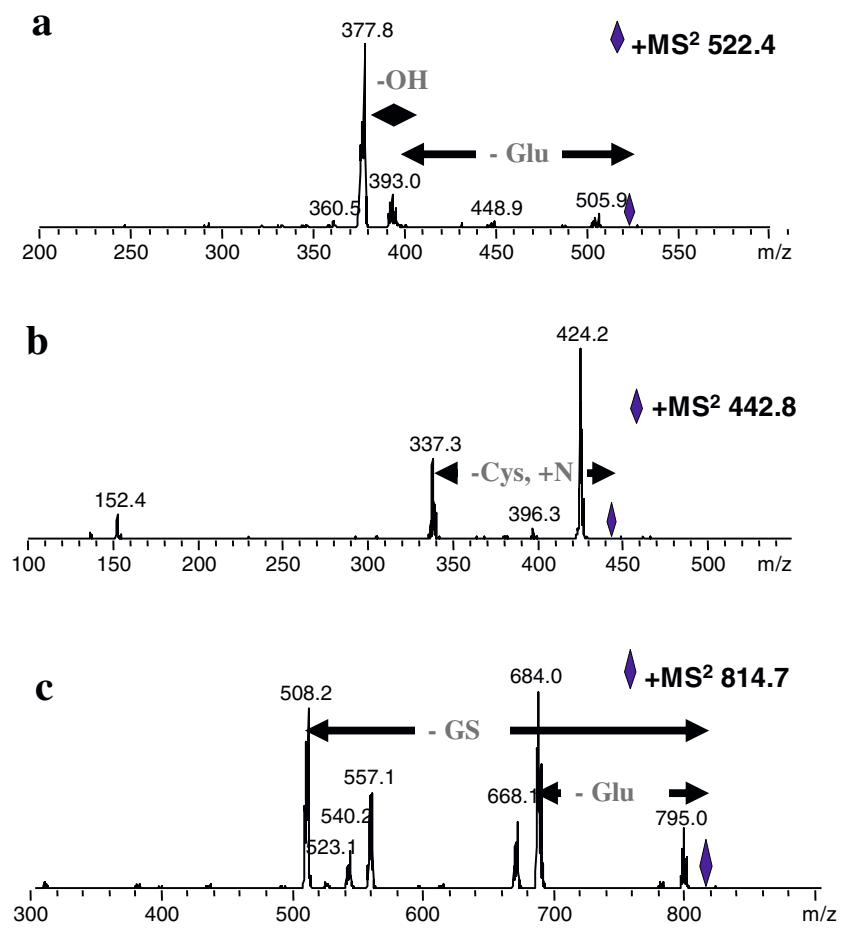

Fig. $5 \mathrm{MS}^{2}$ spectra as obtained from collision-induced fragmentation of the $\mathrm{MH}^{+}$molecular cluster in the ion-trap device from three mercury biothiols. a MeHgGS. b $\mathrm{Hg}(\mathrm{Cys})_{2}$. c $\mathrm{Hg}(\mathrm{GS})_{2}$ 


\section{$\mathrm{MeHgGS}$}

The $\mathrm{MS}^{2}$ of MeHgGS shows one high-abundance fragment at $m / z 375$, corresponding to the loss of a Glu moiety and $\mathrm{OH}$, plus two low-abundance fragments at $\mathrm{m} / \mathrm{z} 509$ (loss of $\mathrm{H}_{2} \mathrm{O}$ ) and $m / z 393$ (loss of Glu). GS is not lost during this fragmentation, but rather the Glu moiety is chopped off the GS. Interestingly, a $\mathrm{MeHg}^{+}$ion fragment that it is formed during $\mathrm{MS}^{2}$ of $\mathrm{HgMeCys}$ cannot be detected either; hence, mercury is probably stabilised by the Gly/Cys moiety.

\section{$\mathrm{Hg}(G S)_{2}$}

The $\mathrm{MS}^{2}$ of $\mathrm{Hg}(\mathrm{GS})_{2}$ shows two main fragments with $\mathrm{m} / \mathrm{z}$ 686 (loss of Glu) and $m / z 508$ (loss of GS), plus four less abundant fragments: $\mathrm{m} / \mathrm{z} 795$ (loss of $\mathrm{H}_{2} \mathrm{O}$ ), and $\mathrm{m} / \mathrm{z}$ 666, $\mathrm{m} / \mathrm{z} 557$ and $\mathrm{m} / \mathrm{z} 547$ formed by successive loss of GS amino acids.

HPLC separation of $\mathrm{HgMeCys}, \mathrm{HgMeGS}, \mathrm{HgCys}_{2}$ and $\mathrm{HgGS}_{2}$ with simultaneous ES-MS and ICP-MS detection

For the chromatographic separation of the mercury biomolecules, HPLC and the simultaneously coupled ES-MS and ICP-MS system was used as described in "Instrumentation". $\mathrm{Hg}(\mathrm{Cys})_{2}$, $\mathrm{HgMeCys}, \mathrm{Hg}(\mathrm{GS})_{2}$ and $\mathrm{HgMeGS}$ solutions were prepared accordingly, as well as a mixture of four compounds with a concentration of $2.5 \mathrm{mg} / \mathrm{L}$ (as $\mathrm{Hg}$ ) each.

Single injections of each standard revealed the retention times for each compound, and these injections were followed by injection of the mixture of the compounds. The elution order obtained was $\mathrm{Hg}(\mathrm{Cys})_{2}, \mathrm{HgMeCys}, \mathrm{Hg}(\mathrm{GS})_{2}$ and $\mathrm{HgMeGS}$, with $\mathrm{HgMeGS}$ being eluted at approximately $9.5 \mathrm{~min}$. All compounds were eluted at a gradient composition of less than $15 \%$ eluent $\mathrm{B}$, showing that relatively soft elution conditions can be applied. Figure 6 shows the combined ICP-MS $\left({ }^{202} \mathrm{Hg},{ }^{103} \mathrm{Rh}\right)$ and ES-MS traces for the extracted ion chromatograms of $m / z$ for $\mathrm{MH}^{+}$ for the four mercury species.

The ES-MS traces of the extracted ion chromatograms show distinct peaks of the protonated molecular ion masses. For each compound, the same isotope cluster was found as was obtained in the flow-injection experiments with the single species. Moreover, the $\mathrm{MS}^{+}$spectra (in-source fragmentation) are identical to those obtained in the directinjection experiment, as are the $\mathrm{MS}^{2}$ spectra of the $\mathrm{MH}^{+}$ molecular ions (data not shown).

All ion traces in ES-MS are on the same $y$-scale, and it is evident that the intensities measured in ES-MS are speciesdependent, like in the direct-injection experiments. MeHgGS shows the highest intensity, approximately 10 times higher than MeHgCys. Although a methanol gradient was used in the HPLC experiment $(12.5 \%$ methanol at 10 min retention

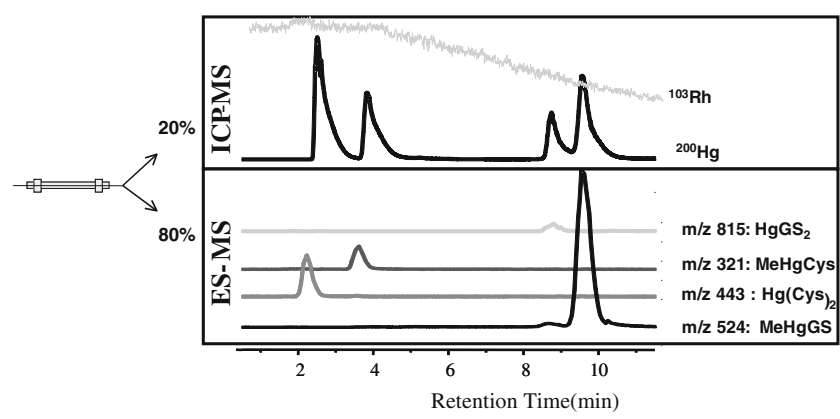

Fig. 6 Simultaneous ICP-MS and ES-MS spectra from high-performance liquid chromatography injection of $\mathrm{MeHgCys}, \mathrm{MeHgGS}, \mathrm{Hg}(\mathrm{Cys})_{2}$ and $\mathrm{Hg}(\mathrm{GS})_{2}$

time), the relative peak intensities are comparable with those obtained with the direct injections.

A different picture is seen for the ICP-MS signal for mercury. In ICP-MS, all compounds should be completely destroyed by the hard ionisation conditions in the plasma. Therefore, the signal intensities for the different compounds should only be governed by the absolute mercury concentration. As all the compounds were made up in the same concentration (as $\mathrm{Hg}$ ), the ICP-MS response should be very similar for all compounds. Figure 6 shows that for the four compounds the intensities obtained are much more similar than those obtained by ES-MS, but are not ideally equal: the peaks corresponding to the first and the last species eluted $\left(\mathrm{HgCys}_{2}\right.$ and $\left.\mathrm{MeHgGS}\right)$ are approximately twice the peaks obtained for $\mathrm{MeHgCys}$ and $\mathrm{HgGS}_{2}$. Several reasons can be responsible for this finding:

- Overall intensity changes due to the input of methanol into the plasma. As shown in Fig. 6, the signal for the internal standard is constant up to approximately $4 \mathrm{~min}$ of runtime; afterwards it decreases to about $50 \%$ of the initial value at 10 -min runtime, when the last mercury compound is eluted. If the mercury intensities are influenced by this process only, the signals for the first compounds eluted (both less than 4 min retention time) should be equal, whereas the signals for the GS complexes should be only about half. This is not the case; in fact the last compound eluted, MeHgGS, exhibits a signal equal to the first compound eluted. However, the behaviour of mercury with its high ionisation potential $(10.4 \mathrm{eV})$ is greatly influenced by organic matter in the plasma, and the mercury signal intensity may change in a different way from the intensity of rhodium. The dependence of the mercury intensity on the methanol content of the eluent must be determined, but this was not performed during the experiments reported here.

- The volatilities of the compounds may be different, so different amounts of each compound may be introduced into the plasma during pneumatic nebulisation: 


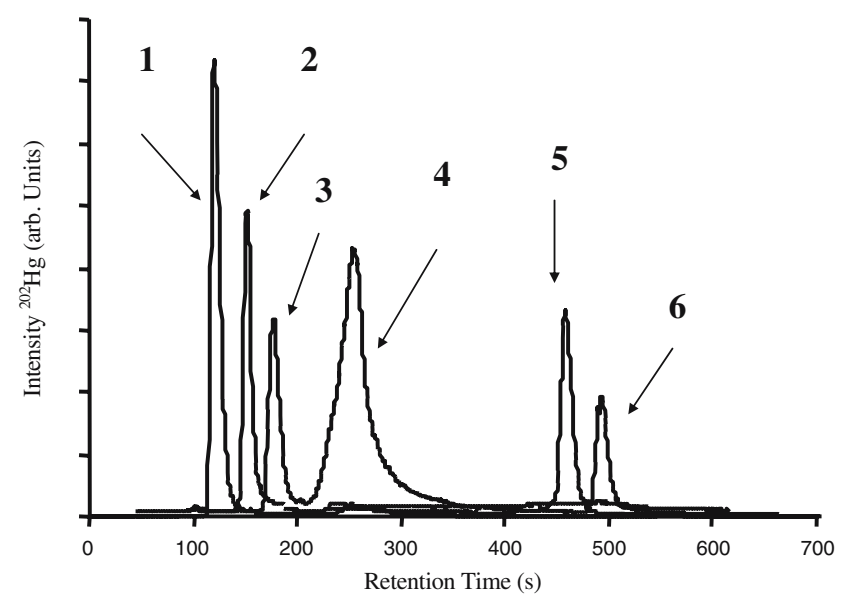

Fig. 7 Overlaid chromatograms for injections of free and biothiolcomplexed mercury species in a plant extract spiked with different $\mathrm{Hg}$ and $\mathrm{HgMe}$ biothiol complexes. Peak assignment: $1 \mathrm{Hg}(\mathrm{Cys})_{2}, 2 \mathrm{Hg}^{2+}$, $3 \mathrm{MeHgCys}, 4 \mathrm{MeHg}^{+}$, $5 \mathrm{MeHgGS}, 6 \mathrm{Hg}(\mathrm{GS})_{2}$

this effect is well known for volatile species like $\mathrm{HgMe}_{2}$, and has to be investigated further for the compounds used in this experiment.

- MeHgCys and $\mathrm{HgGS}_{2}$ may partly decompose on the column, so not all of the compound injected may reach the plasma: in this case, we would expect broad, tailing peaks and substantial amounts of free Cys and reduced GS. However, these have not been observed.

- MeHgCys and $\mathrm{HgGS}_{2}$ are not present to $100 \%$ in the standard, and thus the concentrations of the mercury reaching the plasma are diminished: in this case, signals for unbound Cys and GS should show also significant intensity. In fact, some oxidised Cys and oxidised GS can be distinguished in the ES-MS, but is not clear whether the amounts may sum up to explain the intensity loss in MeHgCys and $\mathrm{HgGS}_{2}$. However, the corresponding mercury part of the molecules $\left(\mathrm{Hg}^{2+}\right.$ and $\mathrm{MeHg}$ ) should show up in the ICP-MS trace, and this is not the case. As shown further later for the spiking experiments (Fig. 7), $\mathrm{Hg}^{2+}$ and $\mathrm{HgMe}^{+}$are eluted from the column with distinct retention times differing from the retention times of the other complexes.

Thus, a final explanation for the difference in intensity of the four compounds cannot be given at this point.

Compound stability during spiking experiments of plant extracts

The mercury biomolecules synthesised and characterised here shall be detected and identified in real-world samples. One future application is the determination of such compounds in plants exposed to mercury contamination. Mercury can readily be taken up by plants, can accumulate in the roots and can be translocated into shoots and fruits $[16,17,27,28]$.

For the determination of such complexes in plant material, the latter has to be extracted using a minimally invasive method which does not destroy or transform the compounds we are looking for. Here, we tested the stability of the four example compounds in extracts from roots and shoots of rice plants.

The plant extracts, prepared as described earlier, were spiked with the four compounds and the signals obtained were compared with the corresponding signals when the compounds were prepared in $0.1 \%$ formic acid. Simultaneous ES-MS and ICP-MS detection was applied using the same setup as described earlier. Additionally, plant extracts were spiked with "free" $\mathrm{Hg}^{2+}$ and $\mathrm{HgMe}^{+}$in order to determine their retention behaviour on the column, and to see whether any complexes would form in situ with any biothiols possibly present in the plant extracts.

Table 3 Retention times for consecutive injection of six mercury compounds with $7 \mathrm{~h}$ difference

\begin{tabular}{|c|c|c|c|c|c|c|}
\hline Sample & $\mathrm{HgCys}_{2}$ & $\mathrm{Hg}^{2+}$ & $\mathrm{MeHgCys}$ & $\mathrm{MeHg}^{+}$ & $\mathrm{HgGS}_{2}$ & MeHgGS \\
\hline Standard 1 & 120.7 & 152 & 213.5 & 302 & 458.4 & 529.1 \\
\hline Standard 2 & 120.7 & 152 & 218.5 & 303 & 454.1 & 527.7 \\
\hline Roots extract 1 & 125.7 & NA & 213.5 & 286 & 457.8 & 529.8 \\
\hline Roots extract 2 & 126 & NA & 212.8 & 284.9 & 452.7 & 526.9 \\
\hline Shoots extract 1 & 125.7 & 150.6 & 213.5 & 295.6 & 457.7 & 529.1 \\
\hline Shoots extract 2 & 125 & 151.4 & 214.2 & 292.8 & 455.5 & 526.2 \\
\hline Average & 123.9 & 151.5 & 214.3 & 294.1 & 456.0 & 528.1 \\
\hline$\sigma$ & 2.5 & 0.66 & 2.1 & 7.7 & 2.3 & 1.4 \\
\hline RSD (\%) & 2.0 & 0.4 & 0.9 & 2.6 & 0.5 & 0.3 \\
\hline
\end{tabular}

$N A$ not available, $R S D$ relative standard deviation 
In Fig. 7, the ${ }^{202} \mathrm{Hg}$ traces monitored by ICP-MS are shown for MeHgCys, $\mathrm{Hg}^{2+}, \mathrm{Hg}(\mathrm{Cys})_{2}, \mathrm{MeHg}^{+}, \mathrm{Hg}(\mathrm{GS})_{2}$ and $\mathrm{MeHgGS}$ spiked into the shoot extract of a rice plant at a concentration of $10 \mathrm{mg} / \mathrm{kg}$ (as $\mathrm{Hg}$ ) each. It is evident that the elution order of the four mercury biothiol complexes matches very well the one obtained in a standard mixture (Fig. 6). Surprisingly, $\mathrm{Hg}^{2+}$ is eluted later than $\mathrm{HgCys}_{2}$, whereas $\mathrm{MeHg}^{+}$is eluted with a broad peak with a retention time of approximately $5 \mathrm{~min}$ between the Cys and GS complexes. The elution order and the retention times are practically the same for the standard, root and shoot extracts, and this also remains over time: a second injection of all samples, done $7 \mathrm{~h}$ after the first run, showed no significant change in retention times. A similar picture is seen for the peak areas. Except for $\mathrm{Hg}^{2+}$ and $\mathrm{MeHgCys}$, the peak areas measured after $7 \mathrm{~h}$ are more than $80 \%$ of the initial value (peak areas corrected for instrumental drift using the internal standard signal). Surprisingly, MeHgCys turns out to be more stable in the extracts than in the standard solution. This might be due to the presence of some unidentified chelating agents. The peak area for $\mathrm{Hg}^{2+}$ varies considerably, showing a 50\% rise for the standard in $0.1 \%$ formic acid, whereas a $30 \%$ decrease is observed in the plant extract. While no explanation can be given here for the intensity rise of the $\mathrm{Hg}^{2+}$ peak in the standard, in the shoot extract the formation of other, unidentified mercury complexes may be proposed.

The results for retention time and peak intensity reproducibility are summarised in Tables 3 and 4 .

The addition of $\mathrm{MeHg}^{+}$to the extracts did not result in any additional peaks in the ICP-MS trace, while for the addition of $\mathrm{Hg}^{2+}$ a small, very broad peak can be distinguished around the retention time of HgMeGS. An elevated mercury background is seen after the introduction of $\mathrm{Hg}^{2+}$ to the standard and the extract, pointing to some kind of exchange on the HPLC column, possibly through formation of unidentified, labile complexes. However, the mercury counts are at the normal background level again prior to injection of the next sample. Regarding the ES-MS measurements (data not shown), the same $\mathrm{MH}^{+}$ion cluster patterns are found for the four spiked mercury complexes as in the standards. As already seen from the ICP-MS traces, addition of $\mathrm{Hg}^{2+}$ or $\mathrm{MeHg}^{+}$did not result in the formation of any other distinguishable mercury biothiol compounds. In the unspiked extracts, only trace amounts of free Cys or GS were found, but there was some oxidised and thus inactive GS.

\section{Conclusion and outlook}

In this work, we could successfully show the synthesis, structural identification and HPLC separation of mercury and methylmercury complexes with Cys and GS. An ESMS system equipped with an ion trap for $\mathrm{MS}^{2}$ measurements revealed characteristic $\mathrm{MH}^{+}$and $\mathrm{MS}^{2}$ fragmentation patterns for these compounds, enabling the identification of these or similar complexes in biota samples. The simultaneous coupling of HPLC with ES-MS and ICP-MS with its invaluable combined information on molecular structure and quantitative mercury detection proved to be suited for this kind of compounds. The method described seems to be acceptably robust and reproducible, and also suited for real samples. This was shown through spiking experiments of plant extracts.

However, the quantification approach via the ICP-MS trace needs further investigation, especially in terms of mercury intensity changes due to the gradient introduction of methanol into the plasma, and also in terms of decomposition on column as has been described for As $(\mathrm{GS})_{3}[18]$.

The work presented here is the first step in the determination of mercury species in biota on the molecular level.

Ongoing experiments are aimed at plant exposure to mercury and methylmercury. Here, we can also expect mercury complexes with larger biothiols, especially phytochelatins: phytochelatins are small peptides of the general structure $(\gamma \text {-Glu-Cys })_{n}$-Gly $(n=2-11)$, which can bind to metal ions and play an important role in metal detoxification and translocation processes in plants. Other biota samples, e.g. fish, will be targeted as well.

Finally, this study presents the first identification of mercury and methylmercury biothiols in spiked plant extracts; hence, this method is a novel tool to investigate whether

Table 4 Peak area (as percentage of first measurement) recoveries for consecutive injection of six mercury compounds with $7 \mathrm{~h}$ difference

\begin{tabular}{lllllll}
\hline Sample & $\mathrm{HgCys}_{2}$ & $\mathrm{Hg}^{2+}$ & MeHgCys & $\mathrm{MeHg}^{+}$ & $\mathrm{HgGS}_{2}$ & $\mathrm{MeHgGS}^{2}$ \\
\hline Standard & 91 & 159 & 10 & 98 & 92 & 83 \\
Roots extract & 93 & NA & 67 & 89 & 87 \\
Shoots extract & 96 & 77 & 49 & 95 & 86 & 86 \\
\hline
\end{tabular}


mercury and methylmercury indeed form complexes with biothiols such as Cys and GS, or if they rather bind to larger entities such as phytochelatins in plants or proteins in fish and other biota.

Acknowledgement E.M.K. is thankful for funding through NERC grant no. NE/B505789/1. B.F.M. is the recipient of postdoctoral research fellowship SFRH/BPD/17830/2004 from the Portuguese Ministry for Science, Technology and Higher Education (Foundation for Science and Technology).

\section{References}

1. Clarkson TW, Magos L (2006) Crit Rev Toxicol 36:609-662

2. Sources of error in methylmercury determination during sample preparation, derivatisation detection (Special Workshop Issue) (1999) Chemosphere 39:1037-1224

3. Demuth N, Heumann KG (2001) Anal Chem 73:4020-4027

4. Hintelmann H, Falter R, Ilgen G, Evans RD (1997) Fresenius J Anal Chem 358:363-370

5. Martin-Doimeadios RCR, Krupp E, Amouroux D, Donard OFX (2002) Anal Chem 74:2505-2512

6. Sarica J, Amyot M, Hare L, Blanchfield P, Bodaly RA, Hintelmann H, Lucotte M (2005) Environ Pollut 34:13-22

7. Southworth G, Lindberg S, Hintelmann H, Amyot, M, Poulain A, Bogle MA, Peterson M, Rudd J, Harris R, Sandilands K, Krabbenhoft D, Olsen M (2007) Environ Toxicol Chem 26:53-60

8. Horvat M, Hintelmann H (2007) Anal Bioanal Chem 388:315-317

9. Harris HH, Pickering IJ, George GN (2003) Science 301:1203

10. Morel FMM, Kraepiel AML, Amyot M (1998) Annu Rev Ecol Syst 29:543-566
11. Weiss B, Clarkson TW, Simon W (2002) Environ Health Perspect 110:851-854

12. Zalups RK (2000) Pharmacol Rev 52:113-143

13. Bridges CC, Zalups RK (2006) Toxicol Appl Pharm 204:274-308

14. Hoffmeyer RE, Singh SP, Doonan CJ, Ross ARS, Hughs RJ, Pickering IJ, George GN (2006) Chem Res Toxicol 19:753-756

15. Schmöger MEV, Oven M, Grill E (2000) Plant Physiol 122:793801

16. Rodriguez L, Rinçon J, Asenico I, Rodriguez-Castellanos L (2007) Int J Phytoremediat 9:1-13

17. Du X, Zhu YG, Liu WJ, Zhao XS (2005) Environ Exp Bot 54:1-7

18. Raab A, Meharg AA, Jaspars M, Genney DR, Feldmann J (2004) J Anal At Spectrom 19:183-190

19. Bluemlein K, Raab A, Meharg AA, Feldmann J (2008) Anal Bioanal Chem. DOI 10.1007/s00216-007-1724-y

20. Schmidt MW, Baldridge KK, Boatz JA, Elbert ST, Gordon MS, Jensen JH, Koseki S, Matsunaga N, Nguyen KA, Su SJ, Windus TL, Dupuis M, Montgomery JA (1993) J Comput Chem 14:13471363

21. Hehre WJ, Ditchfield R, Pople JA (1972) J Chem Phys 56:22572261

22. Stevens WJ, Krauss M, Basch H, Jasien PG (1992) Can J Chem 70:612-630

23. Goodman JM (1998) Chemical applications of molecular modelling. 1st edn. Royal Society of Chemistry, Cambridge

24. Mount Lab (2005) Hoagland's solution (plant nutrient solution). http://amadeus.biosci.arizona.edu/ jdhall/Protocols/PlantNutrient Solution.doc. Accessed Nov 2007

25. Raab A, Feldmann J, Meharg AA (2004) Plant Physiol 134 (3):1113-1122

26. D’Agostino A, Colton R, Traeger JC, Canty AJ (1996) Eur Mass Spectrom 2:273-285

27. Israr M, Sahi S, Datta R, Sarkar D (2006) Chemosphere 65:591-598

28. Velasco-Alinsug MR, Rivero GC, Quibuyen TAO (2005) Z Naturforsch C 60:252-259 